\title{
Type D personality and self-esteem in conversion disorder: a case-control study
}

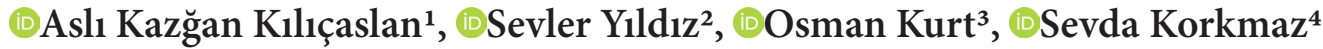 \\ ${ }^{1}$ Bozok University, Department of Psychiatry, Yozgat, Turkey \\ ${ }^{2}$ Binali Yıldırım University, Department of Psychiatry, Erzincan, Turkey \\ ${ }^{3}$ Firat University, Medical Faculty, Department of Public Health, Elazığ, Turkey \\ ${ }^{4}$ Firat University, Medical Faculty, Department of Psychiatry, Elazığ, Turkey
}

Cite this article as: Kazğan Kılıçaslan A, Yıldız S, Kurt O, Korkmaz S. Type D personality and self-esteem in conversion disorder: a casecontrol study. J Health Sci Med 2021; 4(6): 816-823.

\begin{abstract}
Aim: In the present study, we aimed to investigate the differences in type D personality and self-esteem between patients with conversion disorder (CD) and the control group.

Material and Method: We carried out the study with 100 patients diagnosed with CD and 100 matching healthy individuals. We used a sociodemographic information form, the Type D Personality Scale (DS-14), and the Rosenberg Self-Esteem Scale (RSES) as the data collection tools. Considering that the scales should have high discriminative powers, we calculated the cutoff points on each scale performing the ROC analysis.

Results: The results showed that the patients with CD had significantly higher negative affectivity (NA), social inhibition (SI), and DS-14 total scores than the control group $(\mathrm{p}<0.001)$. Also, the patient group obtained significantly higher scores on the RSES than the control group, indicating lower self-esteem among the patients $(\mathrm{p}<0.001)$. Finally, we concluded significant positive correlations between the RSES scores and NA ( $\mathrm{r}=0.549 \mathrm{p}<0.001)$, SI $(\mathrm{r}=0.410 \mathrm{p}<0.001)$ and DS-14 total scores ( $\mathrm{r}=0.521$ $\mathrm{p}<0.001)$.

Conclusion: Overall, we found that CD patients had type D personality traits and low self-esteem. As the patients had decreased self-esteem, their DS-14 scores increased. Uncovering SI and NA to be high in these patients may drive physicians to take measures to mitigate these situations and adopt a different perspective on CD. In addition, the results may contribute to better addressing patients' conversion symptoms and personality traits compatible with CD.
\end{abstract}

Keywords: Conversion disorder, type D personality, self-esteem

\section{INTRODUCTION}

Conversion disorder $(\mathrm{CD})$ is a psychiatric disorder that causes functionality loss, usually following a stressful life event, with evidence of divergent symptoms of one or more voluntary motor/sensory function alterations with neurological or general medical conditions (1). The Diagnostic and Statistical Manual of Mental Disorders, Fourth Edition (DSM-IV) covers CD as a diagnosis under somatoform disorders (2). In the fifth edition of the manual (DSM-V), it is defined as "Functional Neurological Symptom Disorder" under "Somatic Symptom Disorders and Related Disorders" (1). The lifetime prevalence of somatoform disorders is $0.1-0.5 \%$ (3). Besides, the CD is the most prevalent somatoform disorder; its incidence in Turkey was previously reported to be $4.5-32 \%$ (4). Previous large-scale population-based studies reported the incidence rates to range from 0.04 to $12 \%$ (5). The conversion disorder is often accompanied by another mental disorder; major depressive disorder is shown to be the most common accompanying disorder at a rate of $17-29 \%(6)$.

Personality is conceived of temperament and character traits (7). Some personality traits are considered significant predisposing factors for psychiatric disorders. In this respect, it was reported that patients with somatic symptoms in somatization disorder have more primitive, dependent, and egocentric traits (7). In the relationship between $\mathrm{CD}$ and personality, relevant research showed that difficult temperament causes internalization of behavioral problems in children, whereas easy temperament works in preventing the 
emergence of psychological disorders (8). Another study on the relationship between character traits and $\mathrm{CD}$ reported that children with $\mathrm{CD}$ had a more dominant negative mood (frustrated, angry, discontented/irritated) compared to controls (9). The same study also mentioned that temperament is a likely factor for CD development in children (9). Yet, there are quite limited studies investigating personality traits in $\mathrm{CD}$ in adult groups $(10,11)$. Some of such studies reported low neurotic tendencies and personal adjustment among the patients (11).

Individuals with type D personality are those who can easily have negative emotions, such as anger and tension, and experience such emotions more than positive ones (12). At the same time, these individuals are likely to be introverted and tend to be disturbed in settings with strangers. Type D personality consists of social inhibition (SI) in conjunction with negative affectivity (NA). $\mathrm{NA}$ is defined as a tendency to experience depressive affect, restlessness, irritability, and hostility. SI, on the other hand, is the tendency to prevent the expression of emotions in social spheres. Individuals with high NA experience dysphoria, anxiety, and irritability more frequently. Those with high SI often feel anxious and insecure when they are with others (12). Substantial evidence shows that these individuals have higher levels of stress and experience more physical complaints when compared to the general population (13). A recent study reported that $91 \%$ of patients with type D personality had at least one somatic disorder, and $10 \%$ had at least three somatic disorders (14). Type D personality prevalence is often reported to be $13 \%-24 \%$ in the general population (15). In addition, the literature points out that type D personality traits are associated with suicidal thoughts in depressive disorder $(16,17)$. In type D personality, negative thoughts may also impair self-esteem.

Self-esteem is the ability to value oneself and make accurate assessments of oneself; it is a measure of seeking approval, acceptance, and self-confidence (17). It is known that psychological disorders adversely affect self-esteem is affected (18). When it comes to CD, patients embody their feelings and thoughts, which they perceive to be unacceptable, through symptoms. Using these signals, one may attract the attention of those around them and make their own existence accepted (1). Individuals with type D personality traits are often dissatisfied with their lives and have low self-esteem (12).

Although studies exploring CD frequently address temperament and character traits, they seem to miss type $\mathrm{D}$ personality patterns in $\mathrm{CD}(10,11,19)$. Therefore, this study aimed to compare type D personality traits and self-esteem in individuals diagnosed with CD upon DSM-5 criteria with the control group. We hypothesized that $\mathrm{CD}$ patients might show type $\mathrm{D}$ personality traits, consisting of a combination of NA and SI, more than healthy controls and that the same group might have lower self-esteem than the control group.

\section{MATERIAL AND METHOD}

This study was approved by Non-interventional Researchs Ethics Committee of Firat University (Date: 14.01.2021, Decision No: 2021/01-07). After being informed about the purpose of the study, all the participants provided their written consent to participate in the study voluntarily. All procedures were carried out in accordance with the ethical rules and the principles of the Declaration of Helsinki.

We recruited a total of 100 patients who applied to the Firat University psychiatry clinic and were treated as either inpatient or outpatient and diagnosed with $\mathrm{CD}$ by a psychiatrist according to DSM-5 diagnostic criteria. We carried out the study with only those 18-65 years, without any important physical pathology or physical disorder that may affect the distribution of psychiatric symptoms, without alcohol and substance abuse, and without any other accompanying psychiatric disorder.

For the healthy control group, we selected a total of 100 individuals among healthcare staff and patient relatives who could match the patient group regarding sociodemographic data, such as age, sex, educational attainment, and did not have any psychiatric disorder.

Initially, we reached out to $153 \mathrm{CD}$ patients for the study but could not include five people because they refused to participate in the study voluntarily. Of the remaining 148 patients, we had to exclude 42 due to another comorbid psychiatric disorder. Finally, we did not evaluate the data from 6 patients due to missing data on their questionnaires. A psychiatry specialist collected the data using a sociodemographic information form, the DS-14, and the RSES. It took approximately 35 minutes each to administer the questionnaires to the participants.

\section{Data Collection Tools}

1) Sociodemographic Information Form: We prepared the form in line with the overall purpose of the study. It is a form covering demographic information, such as age, marital status, educational attainment, place of residence, and employment and economic status, as well as clinical evaluation inquiries, such as duration of the psychiatric disorder, presence of any psychosocial stress factors, inpatient treatment history, and smoking or alcohol use.

2) Type D Personality Scale (DS-14): The scale was developed particularly to assess NA, SI, and Type D personality. The items of DS-14 were derived from DS16 (20), but the scale also contains new items aimed at 
enhancing the assessment of NA and SI (12). The DS14 includes 14 items in total equally distributed to two subscales measuring NA and SI. It is a four-point (0-4) Likert-type scale. The total score ranges from 0 to 28 for both subscales, and the cut-off point is $\geq 10$ for each subscale (15). Öncü et al. (21) carried out the validity and reliability study of the scale in the Turkish context. Accordingly, the researchers found Cronbach's alpha values to be $\alpha=0.82$ for the NA subscale and $\alpha=0.81$ for the SI subscale. In this study, we calculated these values to be 0.80 and 0.79 , respectively.

3) Rosenberg Self-Esteem Scale (RSES): The scale developed by Rosenberg (22) attempts to determine the self-esteem levels of patients based on their own perceptions. The 63-item scale has 12 subscales; we used only the 10-item "Self-Esteem" subscale in this study. The items on this subscale are rated on a scale ranging from 0 to 6 points. Accordingly, those scoring $0-1,2-4$, and $5-6$ on the subscale are considered to have high, moderate, and low self-esteem, respectively. Çuhadaroğlu (23) performed the Turkish validity and reliability study of the scale. In the Turkish version, the researcher found Cronbach's a value to be 0.76 . In this study, we calculated the internal consistency of the "Self-Esteem" subscale to be 0.75 .

\section{Statistical Analysis}

We performed all statistical analyses on SPSS (Statistical Package for Social Sciences; SPSS Inc., Chicago, IL). In the study, we presented categorical variables in number and percentage, while continuous variables were shown in mean \pm standard deviation, median, interquartile range (25-75 percentiles). We run a Chi-square analysis to compare categorical data. Besides, we performed a Kolmogorov-Smirnov test to check whether the continuous variables showed a normal distribution. Then, for non-normally distributed data, we used a Mann-Whitney $U$ test to compare non-normally distributed variables between two groups, while the data were compared using a Kruskal-Wallis test between more than two groups. We calculated Spearman's correlation coefficients to reveal relationships between continuous variables. We drew Receiver-operating characteristic (ROC) curves to measure the diagnostic values of DS and RSES. Finally, we considered $\mathrm{p}<0.05$ statistically significant in all statistical analyses.

\section{RESULTS}

We carried out the study with a total of 200 individuals, $100 \mathrm{CD}$ patients and 100 healthy controls. While the mean age of the patient group was $29.3 \pm 7.8$ ( $\mathrm{min}=18$, $\max =50)$, the control group had a mean age of $28.6 \pm 7.9$ $(\min =18, \max =47)$. We detected $67 \%$ of the patients had a psychosocial stress factor.
The results revealed no significant differences between the patient and control groups by sex, marital status, educational attainment, place of residence, economic status, occupation, and organic disorder $(\mathrm{p}>0.05)$ (Table 1).

We found that the patient group had significantly more psychiatric treatment history, family history of psychiatric disorder, and smoking than the control group $(\mathrm{p}<0.001)$ (Table 1). In addition, we discovered the participants with secondary school and below education (35.5\%) had significantly more multiple symptoms than those with high school and above education (16.2\%) $(\mathrm{p}=0.039)$.

Table 1. Sociodemographic and disorder-related characteristics of the groups

\begin{tabular}{|c|c|c|c|c|c|}
\hline & \multicolumn{2}{|c|}{ Patients } & \multicolumn{2}{|c|}{ Controls } & \multirow[t]{2}{*}{$\mathbf{p}$} \\
\hline & n & $\%$ & $\mathbf{n}$ & $\%$ & \\
\hline $\begin{array}{l}\text { Age, Median } \\
\text { (IQR) }\end{array}$ & $\begin{array}{c}28 \\
(23-35)\end{array}$ & & $\begin{array}{c}28 \\
(22-34)\end{array}$ & & $0.461^{\star}$ \\
\hline Sex & & & & & $0.339^{* *}$ \\
\hline Female & 70 & 70.0 & 76 & 76,0 & \\
\hline Male & 30 & 30.0 & 24 & 24,0 & \\
\hline Marital status & & & & & $0.777^{\star *}$ \\
\hline Single & 51 & 51.0 & 53 & 53.0 & \\
\hline Married & 49 & 49.0 & 47 & 47.0 & \\
\hline \multicolumn{3}{|c|}{ Educational Attainment } & & & $0.884^{* *}$ \\
\hline $\begin{array}{l}\text { Secondary school } \\
\text { and below }\end{array}$ & 62 & 62.0 & 61 & 61.0 & \\
\hline $\begin{array}{l}\text { High school and } \\
\text { above }\end{array}$ & 38 & 38.0 & 39 & 39.0 & \\
\hline \multicolumn{2}{|l|}{ Place of Residence } & & & & $0.885^{\star *}$ \\
\hline District & 40 & 40.0 & 41 & 41.0 & \\
\hline City & 60 & 60.0 & 59 & 59.0 & \\
\hline \multicolumn{2}{|l|}{ Economic status } & & & & $1,000^{\star *}$ \\
\hline Low & 46 & 46.0 & 46 & 46.0 & \\
\hline Middle & 54 & 54.0 & 54 & 54.0 & \\
\hline \multicolumn{2}{|l|}{ Profession } & & & & $0.874^{\star *}$ \\
\hline Housewife & 28 & 28.0 & 29 & 29.0 & \\
\hline Student & 5 & 5.0 & 5 & 5.0 & \\
\hline Civil servant & 16 & 16.0 & 16 & 16.0 & \\
\hline Worker & 28 & 28.0 & 22 & 22.0 & \\
\hline Unemployed & 23 & 23.0 & 28 & 28.0 & \\
\hline \multicolumn{2}{|l|}{ Physical disorder } & & & & $0.065^{\star *}$ \\
\hline Yes & 7 & 7.0 & 1 & 1.0 & \\
\hline No & 93 & 93.0 & 99 & 99.0 & \\
\hline \multicolumn{3}{|c|}{ Psychiatric treatment history } & & & $<0.001^{* *}$ \\
\hline Yes & 32 & 32.0 & 4 & 4.0 & \\
\hline No & 68 & 68.0 & 96 & 96.0 & \\
\hline \multicolumn{4}{|c|}{ History of family psychiatric disorder } & & $<0.001^{* *}$ \\
\hline Yes & 37 & 37.0 & 6 & 6,0 & \\
\hline No & 63 & 63.0 & 94 & 94.0 & \\
\hline Smoking & & & & & $<0.001^{* *}$ \\
\hline Yes & 31 & 31.0 & 6 & 6,0 & \\
\hline No & 69 & 69.0 & 94 & 94.0 & \\
\hline Childhood trauma & & & & & $<0.001^{* *}$ \\
\hline Yes & 45 & 45.0 & 22 & 22.0 & \\
\hline No & 55 & 55.0 & 78 & 78.0 & \\
\hline
\end{tabular}

Mann Whitney $\mathrm{U},{ }^{*}$ Chi-square analysis; IQR: Interquartile range 
We discovered that the NA, SI, DS-14 total, and RSES scores of the patient group were significantly higher than those of the control group $(\mathrm{p}<0.001)$ (Figure 1). Besides, those with motor symptoms had significantly higher RSES scores than those not showing a motor symptom $(\mathrm{p}=0.02)$ (Table 2).

The NA ( $\mathrm{p}=0.01), \mathrm{SI}(\mathrm{p}=0.031)$, and DS-14 total scores $(\mathrm{p}=0.044)$ of those who had attempted suicide were significantly higher than those who had no suicidal ideation (Table 2). Moreover, we found these scores to be significantly higher in the participants with childhood trauma than those without $(\mathrm{p}<0.001)$ (Table 2).

The results of the correlation analysis showed that there was a positive and significant relationship between the age of onset of treatment and age in the patient group $(\mathrm{r}=0.574 \mathrm{p}<0.001)$. Similarly, in the patient group, the
RSES scores were positively correlated with the NA $(\mathrm{r}=0.549 \mathrm{p}<0.001)$, SI $(\mathrm{r}=0.410 \mathrm{p}<0.001)$ and DS-14 total scores $(r=0.521 \mathrm{p}<0.001)$ (Figure 1).

The results of the ROC analysis on the DS-14 total scores by conversion disorder revealed the cut-off point to be 18. At this cut-off point, we calculated the sensitivity to be $85 \%$, the specificity to be $63 \%$, the positive predictive value to be $69.67 \%$, and the negative predictive value to be $80.77 \%$. Finally, we concluded the area under the curve to be 0.784 . On the other hand, we found the cut-off point to be 1.08 for the RSES scores. At this cutoff point, we calculated the sensitivity to be $57 \%$, the specificity to be $74 \%$, the positive predictive value to be $68.67 \%$, and the negative predictive value to be $63.25 \%$. We found the area under the curve to be 0.659 (Table 3, Figure 2).

\section{Table 2. Participants' scores by various parameters}

\begin{tabular}{|c|c|c|c|c|c|c|c|c|c|}
\hline & & \multicolumn{2}{|l|}{ NA } & \multicolumn{2}{|l|}{ SI } & \multicolumn{2}{|c|}{ DS-14 total } & \multicolumn{2}{|l|}{ RSES } \\
\hline & & Median (IQR) & $\mathbf{p}$ & Median (IQR) & $\mathbf{p}$ & Median (IQR) & $\mathbf{p}$ & Median (IQR) & p \\
\hline \multirow{2}{*}{ Group } & Patient & $17(12-20)$ & \multirow{2}{*}{$<0.001$} & $11(9-16)$ & \multirow{2}{*}{$<0.001$} & $30(21-36)$ & \multirow{2}{*}{$<0.001$} & $1.1(.8-1.7)$ & \multirow{2}{*}{$<0.001$} \\
\hline & Control & $8(6-12.5)$ & & $8(5-11)$ & & $16(12-22)$ & & $1.0(.8-1.1)$ & \\
\hline \multirow{2}{*}{$\begin{array}{l}\text { Psychosocial } \\
\text { stress factor }\end{array}$} & Yes & $18(13-23)$ & \multirow{2}{*}{0.111} & $11(9-16)$ & \multirow{2}{*}{0.685} & $31(22-36)$ & \multirow{2}{*}{0.123} & $1.2(1.0-1.8)$ & \multirow{2}{*}{0.239} \\
\hline & No & $16(8-20)$ & & $12(7-17.5)$ & & $29(17-33.5)$ & & $1.1(.8-1.4)$ & \\
\hline \multirow{2}{*}{$\begin{array}{l}\text { Secondary } \\
\text { benefit }\end{array}$} & Yes & $17.5(11-23.5)$ & \multirow{2}{*}{0.601} & $11(9-16.5)$ & \multirow{2}{*}{0.830} & $30(20.5-36)$ & \multirow{2}{*}{0.806} & $1.2(.9-1.7)$ & \multirow{2}{*}{0.457} \\
\hline & No & $17(13-20)$ & & $12(9-16)$ & & $30(21-35)$ & & $1.1(.8-1.7)$ & \\
\hline \multirow{2}{*}{ Motor symptom } & Yes & $17(15-20)$ & \multirow{2}{*}{0.457} & $11(10-15)$ & \multirow{2}{*}{0.344} & $30(26-35)$ & \multirow{2}{*}{0.458} & $1.3(1.1-1.8)$ & \multirow{2}{*}{0.02} \\
\hline & No & $17.5(10-21)$ & & $11.5(8-17)$ & & $31(19-36)$ & & $1.1(.8-1.6)$ & \\
\hline \multirow{2}{*}{$\begin{array}{l}\text { Sensory } \\
\text { symptom }\end{array}$} & Yes & $18(13-20)$ & \multirow{2}{*}{0.655} & $12(9-15)$ & \multirow{2}{*}{0.926} & $30(20-36)$ & \multirow{2}{*}{0.917} & $1.1(.8-1.5)$ & \multirow{2}{*}{0.330} \\
\hline & No & $17(12-20)$ & & $11(9-16)$ & & $30(21-36)$ & & $1.2(.8-1.8)$ & \\
\hline \multirow{2}{*}{ Pseudo seizure } & Yes & $18(11-23)$ & \multirow{2}{*}{0.769} & $11(8-16)$ & \multirow{2}{*}{0.331} & $29.5(20-36)$ & \multirow{2}{*}{0.694} & $1.2(.8-1.8)$ & 0259 \\
\hline & No & $17(13-20)$ & & $13(10-18)$ & & $30(22-35)$ & & $1.1(.8-1.5)$ & \\
\hline & None & $16.5(11-20)$ & & $11(8-17)$ & & $29.5(19-35)$ & & $1.2(.8-1.7)$ & \\
\hline Treatment & Irregular treatment & $18(12-24)$ & 0.194 & $14(9-16)$ & 0.671 & $31(20-36)$ & 0.393 & $1.1(1.0-1.5)$ & 0.474 \\
\hline & Regular treatment & $18.5(16-20)$ & & $11.5(10-15)$ & & $30.5(27.5-35)$ & & $1.2(1.0-1.8)$ & \\
\hline Hosnitalization & Yes & $18.5(14.5-24)$ & 0264 & $11.5(9.5-14.5)$ & 0.920 & $30(24-36)$ & 0,568 & $1.2(1.1-1.5)$ & 0.51 \\
\hline Hospitallzation & No & $17(11-20)$ & 0.204 & $11(9-17)$ & 0.920 & $30(20-36)$ & 0.500 & $1.1(.8-1.7)$ & 0.510 \\
\hline Sulcid & Yes & $24(24-26)$ & 001 & $17(14-20)$ & 00 & $35(31-46)$ & 10 & $1.7(1.2-2.2)$ & 017 \\
\hline suiciae & No & $17(12-20)$ & 0.01 & $11(9-16)$ & 0.031 & $30(21-36)$ & 0.044 & $1.1(.8-1.7)$ & $0.1 / 4$ \\
\hline Childhood & Yes & $17(13-20)$ & $<0001$ & $11(10-15)$ & $<0.001$ & $30(22-34)$ & $<0.001$ & $1.3(1.0-1.8)$ & 60001 \\
\hline trauma & No & $9(7-17)$ & & $9(6-12)$ & & $18(14-29)$ & & $1.0(.7-1.1)$ & \\
\hline
\end{tabular}

Table 3. The results of the ROC analysis

\begin{tabular}{|lcccc|}
\hline & NA & SI & DS-14 total & RSES \\
\hline Cut-off point & 11 & 8 & 18 & 1.08 \\
Sensitivity & $76 \%$ & $78 \%$ & $85 \%$ & $57 \%$ \\
Specificity & $72 \%$ & $56 \%$ & $63 \%$ & $74 \%$ \\
Positive predictive value & $73.08 \%$ & $63.93 \%$ & $69.67 \%$ & $68.67 \%$ \\
Negative predictive value & $75 \%$ & $71.79 \%$ & $80.77 \%$ & $63.25 \%$ \\
AUC (area under the curve) & 0.786 & 0.720 & 0.784 & 0.659 \\
AUC 95 \% confidence interval & $0.722-0.840$ & $0.652-0.781$ & $0.721-0.839$ & $0.589-0.724$ \\
AUC p value & $<0.001$ & $<0.001$ & $<0.001$ & $<0.001$ \\
\hline DS-14: Type D Personality Scale; RSES: Rosenberg Self-Esteem Scale; NA: negative affectivity; SI: social inhibition & & \\
\hline
\end{tabular}




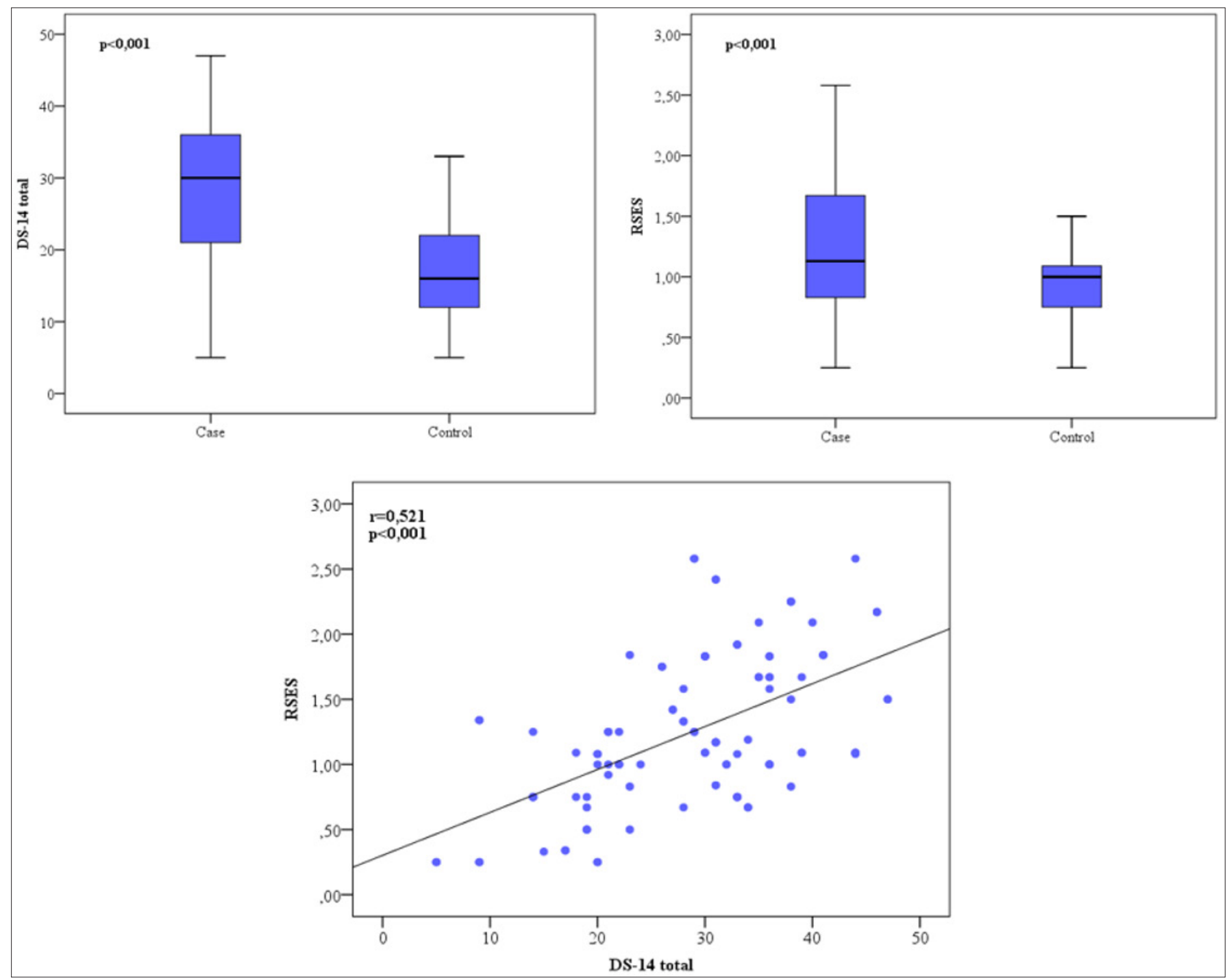

Figure 1. Comparison and correlation of the DS-14 total and RSES scores
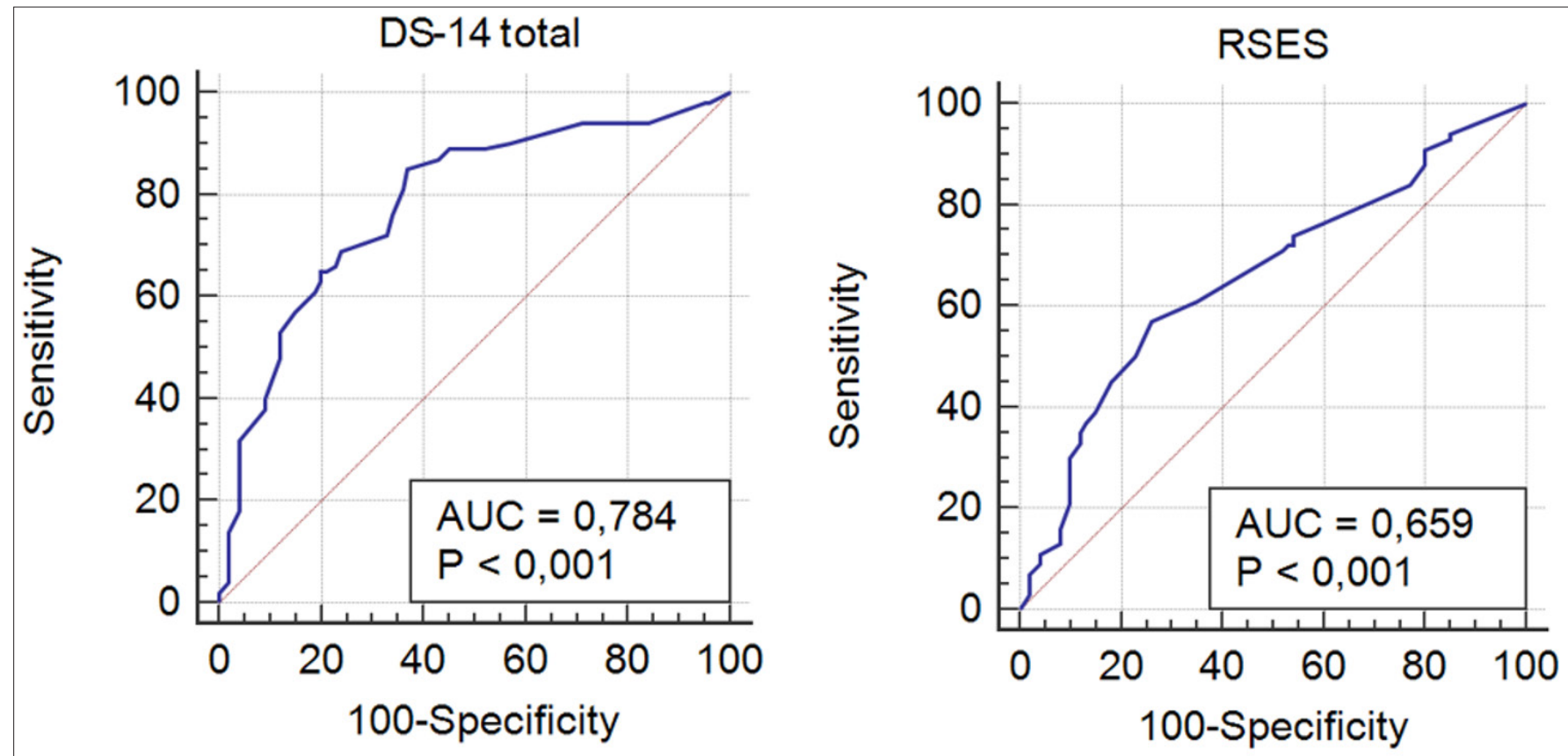

Figure 2. ROC for the DS-14 total and RSES scores 


\section{DISCUSSION}

The DS-14 total, NA, SI, and RSES scores were significantly higher in the patient group than in the control group, which can be considered the most noteworthy finding of the study. The findings also support our hypothesis that CD patients have prevalent type D personality traits along with low self-esteem.

Individuals with type $\mathrm{D}$ personality are generally those who are under chronic stress, prone to negative emotions, such as anxiety and irritability, who cannot find ways to cope with stress, and who often feel socially isolated and lack self-confidence. These people do not share their negative feelings with others for fear of rejection (17). Feeling socially isolated may lead one to feel anxious and suppressed simultaneously, while people with negative affectivity demonstrate more anxiety and physical symptoms (15). Being unable to express negative emotions verbally instead of physically is shown among the causes of conversion disorder (1). Besides, social inhibition is defined as the inhibition tendency in expressing feelings and behaviors due to concerns such as being disliked and not being reciprocated in social relations (12). In our study, we found the SI and NA scores of the patients to be higher than those of the control group. It is already known that anxiety and negative emotions decrease through the symptoms compatible with $\mathrm{CD}$; the same situation may increase one's social acceptance. In case of stress underlying $\mathrm{CD}$, patients may express their social support needs with somatic complaints. When these needs are not met, these individuals may exhibit social withdrawal, introversion, and low cooperation.

In a study, the researchers examined the personality traits of $72 \mathrm{CD}$ patients using the Hacettepe Personality Inventory. As a result, they found the neurotic tendencies and personal adjustment of the patients to be low and attributed low neuroticism to intense use of conversion as a defense mechanism in coping with anxiety (11). Considering the research findings on personality traits in somatoform disorders, patients with somatoform disorder suppress their feelings of inadequacy and exhibit alexithymia, which is defined as difficulty in recognizing and expressing feelings (7). In addition, it was concluded that harm avoidance is prevalent in those adopting somatization excessively (7). These people are also passive, cowardly, and insecure, as well as exhibiting inhibited and shy behaviors in social environments (24). In research utilizing the Temperament and Character Inventory, $\mathrm{CD}$ patients were found to have low levels of self-determination and elevated harm avoidance, as well as showing inadequacy in self-management and cooperation (10). Similar studies with Turkish samples compared $\mathrm{CD}$ patients with healthy controls and concluded that $\mathrm{CD}$ patients had significantly reduced self-directedness $(25,26)$. Nevertheless, except for such limited findings, the research interest seems to miss type $\mathrm{D}$ personality traits in individuals with $\mathrm{CD}$.

One's pessimistic thoughts about the immediate environment can also adversely affect their selfperception. We suppose that one's poor self-perception may cause low self-esteem and frequent psychosomatic symptoms since it is well-known that high self-esteem reduces psychopathological symptoms (27). In the study, the patient group had significantly lower self-esteem than the healthy controls. Both the CD symptoms and the underlying psychiatric reasons may affect one's selfconfidence.

In our study, the DS-14 scores increased as the patients' self-esteem decreased. Similarly, previous research reported that type $\mathrm{D}$ individuals are dissatisfied with their lives and have low self-esteem (11). Type D personality is closely associated with pessimism, perceived lack of social support, low self-esteem, dissatisfaction, and low quality of life (28). Negative thoughts in type D personality may impair self-esteem and are closely related to how one perceives themselves and events and how they establish healthy relationships with others (11). In addition, it is often mentioned that type $\mathrm{D}$ individuals build inadequate rapport with others, contributing to their low self-perception (29).

We discovered the DS-14 total, NA, and SI scores to be significantly higher in $\mathrm{CD}$ patients with a previous suicide attempt. Accordingly, type D personality traits may have predicted suicidal behavior in $\mathrm{CD}$. In the literature, a study found major depressive disorder to be associated with suicidal thoughts in $C D$ patients (16). Other studies also determined the rate of type D personality be significantly higher in those with suicidal ideation (17). Therefore, our findings are consistent with what was previously found in the literature.

The DS-14 total, NA, SI, and RSES scores of CD patients with childhood trauma were also significantly higher. Psychosomatic responses are bodily manifestations of psychological factors. Accordingly, adult patients with prevalent psychosomatic symptoms often have a history of childhood trauma (30). In the same context, we found that that a significant part of the patients (45\%) had at least one traumatic life event (parental separation or loss, neglect, and abuse (sexual-physical-emotional)), which supports the relevant literature. Individuals having experienced childhood trauma may have learned to avoid trauma by producing physical disorders. Just like in type D personality, this situation may prevent them from cooperating and cause them to withdraw from society, become introverted, and have somatic complaints when facing stress. Traumatic events in the 
past may lower one's self-esteem, and such individuals may show symptoms compatible with CD due to their negatively biased cognitive patterns. Traumatic people can also see themselves as worthless and be affected very quickly by any events. Based on our findings, we think that the low self-esteem in the patients may have been because of the adverse effects of self-perception inhibited by past traumas.

Conversion disorder is a disorder that may cause confusion in the diagnosis and fake neurological disorders (1). An auxiliary scale to be used to diagnose CD should have high discriminative power. The results of the ROC analysis on the DS-14 total score by conversion disorder revealed the cut-off point to be 18 . At this cutoff point, we calculated the sensitivity to be $85 \%$ and the specificity to be $63 \%$. On the other hand, we found the cut-off point to be 1.08 for the RSES score. At this cutoff point, we calculated the sensitivity to be $57 \%$ and the specificity to be $74 \%$.

The retrospective nature of this case-control study hinders the generalizability of the results, which can be counted among the limitations to the study. Therefore, conducting experimental and longitudinal studies may help better understand the relationship between self-esteem and type $\mathrm{D}$ personality in $\mathrm{CD}$. Another limitation is that the scales used are all based on self-report (we assumed that all participants provided correct and candid responses to the scale items). Finally, just like CD, the fact that type D personality is seen at a higher rate in females (31) can be a disadvantage for the sample group.

\section{CONCLUSION}

Overall, we found that CD patients had type $\mathrm{D}$ personality traits and low self-esteem. In addition, the DS-14 scores increased as the patients' self-esteem decreased. The finding that $\mathrm{CD}$ patients have low self-esteem may enable us to better deal with their psychosomatic symptoms and social problems. Knowing that SI and NA are high in these patients may drive physicians to take measures to mitigate these situations and adopt a different perspective on $\mathrm{CD}$

\section{ETHICAL DECLARATIONS}

Ethics Committee Approval: This study was approved by Non-interventional Researchs Ethics Committee of Firat University (Date: 14.01.2021, Decision No: 2021/01-07).

Informed Consent: All patients signed the free and informed consent form.

Referee Evaluation Process: Externally peer-reviewed.

Conflict of Interest Statement: The authors have no conflicts of interest to declare.
Financial Disclosure: The authors declared that this study has received no financial support.

Author Contributions: All of the authors declare that they have all participated in the design, execution, and analysis of the paper, and that they have approved the final version.

\section{REFERENCES}

1. American Psychiatric Association. Diagnostic and Statistical Manual of Mental Disorders, 5th Edition (DSM-5). Washington, DC: American Psychiatric Association; 2013.

2. American Psychiatric Association. Diagnostic and Statistical Manual of Mental Disorders, 4th Edition. Washington, DC: American Psychiatric Association; 1994.

3. Koelen JA, Eurelings-Bontekoe EH, van BroeckhuysenKloth SA, Snellen WM, Luyten P. Social cognition and levels of personality organization in patients with somatoform disorders: A casecontrol study. J Nerv Ment Dis 2014; 202: 217-23.

4. Sağduyu A, Rezaki M, Kaplan İ, Özgen G, Gursoy-Rezaki B. Sağlık ocağına başvuran hastalarda dissosiyatif (konversiyon) belirtiler. Turk Psikiyatri Derg 1997; 8: 161-9.

5. Akagi H, House A. The epidemiology of hysterical conversion. In: Halligan PW, Bass C, Marshall JC, eds. Contemporary approaches to the study of hysteria: clinical and theoretical perspectives. Oxford, UK: Oxford University Press; 2001: 73-8.

6. Van Eck van der Sluijs J, Ten Have M, Rijnders C, Van Marwijk H, De Graaf R, Van der Feltz-Cornelis C. Medically unexplained and explained physical symptoms in the general population: Association with prevalent and incident mental disorders. PLoS ONE 2015; 10: e0123274.

7. Okyayuz ÜH, Berksun O, Çevik A. Psikosomatik serviste yatarak tedavi gören hastaların bazı MMPI bulgularının aleksitimik özellikler açısından incelenmesi ve kontrol grubuyla karşılaştırılması. Ankara Üniversitesi DTCF Derg 1991; 35: 195203.

8. Tschann JM, Kaiser P, Chesney MA, Alkon A, Boyce WT. Resilience and vulnerability among preschool children: Family functioning, temperament and behavior problems. J Am Acad Child Adolesc Psychiatry 1996; 35: 184- 92.

9. Krishnakumar P, Sumesh P, Mathews L. Temperamental traits associated with conversion disorder. Indian Pediatr 2006; 43: 8959.

10. Yenilmez Y. The Relationship of temperament and character traits with impulsivity and anger style in conversion disorder. Thesis, Bakirkoy Prof. Dr. Mazhar Osman Training and Research Hospital, Department of Psychiatry, Istanbul; 2011.

11.Uğuz Ş. Other psychopathologies accompanying conversion disorder. Thesis, Çukurova University Faculty of Medicine, Department of Psychiatry, Adana; 1998.

12. TW Smith. Toward a more systematic, cumulative, and applicable science of personality and health: lessons from type D personality. Psychosom Med 2011; 73: 528-32.

13. Allen SF, Wetherell MA, Smith MA. A one-year prospective investigation of type D personality and self-reported physical health. Psychol Health 2019; 34: 773-95.

14. De Vroege L, de Heer EW, van der Thiel E, et al. Type D personality, concomitant depressive and anxiety disorders, and treatment outcomes in somatic symptom and related disorders: an observational longitudinal cohort study. Front Psychiatry 2019; 10: 417 .

15.Denollet J. DS14: standard assessment of negative affectivity, social inhibition, and Type D personality. Psychosom Med 2005; 67: 89-97. 
16. Park YM, Ko YH, Lee MS, Lee HJ, Kim L. Type-D personality can predict suicidality in patients with major depressive disorder. Psychiatry Investig 2014; 11: 232-6.

17. Michal M, Wiltink J, Till Y, et al. Type-D personality and depersonalization are associated with suicidal ideation in the German general population aged 35-74: results from the Gutenberg Heart Study. J Affect Disord 2010; 125: 227-33.

18. Denollet J, Trompetter HR, Kupper N. A review and conceptual model of the association of Type D personality with suicide risk. J Psychiatr Res 2021; 138: 291-300.

19. Ayaz S. Body image and self-esteem in patients with stoma: review. J Med Sci 2008; 28: 154-9.

20.Denollet J. Personality and coronary heart disease:the type D scale 16 (DS16). Ann Behav Med 1998; 20: 209-15.

21. Öncü E, Vasısayoğlu KS. D tipi kişilik ölçeğinin Türk toplumunda geçerlilik ve güvenirlilik çalışması. Ankara Med J 2018; 4: 646-56.

22. Rosenberg M. Conceiving The Self. New York: Basic Books; 1979.

23. Çuhadaroğlu F. Self-esteem in adolescents. Thesis, Hacettepe University Faculty of Medicine, Department of Psychiatry, Ankara; 1986.

24. Russo J, Katon W, Sullivan M, Clark M, Buchwald D. Severity of somatization and its relationship to psychiatric disorders and personality. Psychosomatics 1994; 35: 546-56.

25. Erten E, Yenilmez Y, Fistikci N, Saatcioglu O. The relationship between temperament and character in conversion disorder and comorbid depression. Compr Psychiatry 2013; 54: 354-61.

26. Güleç MY, İnanç L, Yanartaş O, Uzer A, Güleç H. Predictors of suicide in patients with conversion disorder. Compr Psychiatry 2014; 55: 457-62.

27. Garaigordobil M, Perez JI, Mozaz M. Self-concept, self-esteemand psychopatological symptoms. Psicothema 2008; 20: 114-23.

28. Mols F, Denollet J. Type D personality in the general population: A systematic review of health status, mechanisms of disease, and work related problems. Health Qual Life Outcomes 2010; 8: 9.

29. Pederson S, Denollet J. Type D Personality, cardiac events, and impaired quality of life: a review. Eur J Cardiovasc Prev Rehabil 2003; 10: 241-8.

30. Ozcetin A, Belli H, Ertem U, Bahcebasi T, Ataoglu A, Canan F. Childhood trauma and dissociation in women with pseudoseizuretype conversion disorder. Nord J Psychiatry 2009; 63: 462-8.

31. Feinstein A. Conversion disorder: Advances in our understanding. CMAJ 2011; 183: 915-20. 